\title{
Development of Low-Cost Locally Sourced Two- Component Compression Bandages in Western Kenya
}

\author{
Aileen Y. Chang - Edith C. Tonui - Douglas Momanyi · \\ Alex R. Mills · Paul Wasike · Rakhi Karwa - Toby A. Maurer • \\ Sonak D. Pastakia
}

Received: March 22, 2018 / Published online: June 15, 2018

(C) The Author(s) 2018

\begin{abstract}
Introduction: Compression therapy is wellestablished standard of care for chronic leg ulcers from venous disease and lymphedema. Chronic leg ulcers and lymphedema have a significant impact on quality of life, driven by pain, foul odor, and restricted mobility. Provision of layered compression therapy in resource-limited settings, as in Western Kenya and other regions of sub-Saharan Africa, is a major challenge due to several barriers: availability, affordability, and access to healthcare facilities. When wound care providers from an
\end{abstract}

Enhanced digital features To view enhanced digital features for this article go to https://doi.org/10.6084/ m9.figshare.6391919.

A. Y. Chang $(\bowtie) \cdot$ T. A. Maurer

Department of Dermatology, San Francisco School of Medicine, University of California, San Francisco, CA, USA

e-mail: aileen.chang@ucsf.edu

A. Y. Chang · E. C. Tonui · D. Momanyi .

P. Wasike - R. Karwa - T. A. Maurer - S. D. Pastakia Academic Model Providing Access To Healthcare (AMPATH), Eldoret, Kenya

A. R. Mills · R. Karwa · S. D. Pastakia

Department of Pharmacy Practice, Purdue

University School of Pharmacy, West Lafayette, IN, USA

P. Wasike

Department of Pharmacology, Moi University

School of Medicine, Eldoret, Kenya
Academic Model Providing Access to Healthcare (AMPATH) health center in Western Kenya noted that a donated, finite supply of twocomponent compression bandages was helping to heal chronic leg ulcers, they began to explore the potential of finding a local, sustainable solution. Dermatology and pharmacy teams from AMPATH collaborated with health center providers to address this need.

Methods: Following a literature review and examination of ingredients in prepackaged brand-name kits, essential components were identified: elastic crepe, gauze, and zinc oxide paste. All of these materials are locally available and routinely used for wound care. Two-component compression bandages were made by applying zinc oxide to dry gauze for the inner layer and using elastic crepe as the outer layer. Feedback from wound clinic providers was utilized to optimize the compression bandages for ease of use.

Results: Adjustments to assembly of the paste bandage included use of zinc oxide paste instead of zinc oxide ointment for easier gauze impregnation and cutting the inner layer gauze in half lengthwise to facilitate easier bandaging of the leg, such that there were two rolls of zincimpregnated gauze each measuring 5 inches $\times 2 \mathrm{~m}$. Adjustments to use of the compression bandage have included increasing the frequency of bandage changes from 7 to 3 days during the rainy seasons, when it is difficult to keep the bandage dry. Continuous local 
acquisition of all components led to lower price quotes for bulk materials, driving down the production cost and enabling a cost to the patient of 200 KSh (2 USD) per two-component compression bandage kit. Wound care providers have provided anecdotal reports of healed chronic leg ulcers (from venous stasis, trauma), improved lymphedema, and patient tolerance of compression.

Conclusions: Low-cost locally sourced twocomponent compression bandages have been developed for use in Western Kenya. Their use has been initiated at an AMPATH health center and is poised to meet the need for affordable compression therapy options in Western Kenya. Studies evaluating their efficacy in chronic leg ulcers and Kaposi sarcoma lymphedema are ongoing. Future work should address adaptation of compression bandages for optimal use in Western Kenya and evaluate reproducibility of these bandages in similar settings, as well as consider home- or community-based care delivery models to mitigate transportation costs associated with accessing healthcare facilities.

Keywords: Africa; Compression; Kaposi sarcoma; Lymphedema; Paste bandage; Traumatic wound; Unna boot; Venous ulcer

\section{INTRODUCTION}

Chronic leg ulcers have a significant impact on quality of life and pose a considerable socioeconomic burden on patients, resulting from restricted patient mobility leading to inability to work and increased medical costs. While the epidemiology of chronic leg ulcers in sub-Saharan Africa has not been well characterized, studies from other regions indicate that leg ulcers are relatively common, with $60 \%$ of leg ulcers being present for more than 6 months and one-third persisting for over 1 year [1]. Based on the high burden of traumatic soft tissue injuries reported from multiple countries in sub-Saharan Africa [2-5], traumatic injury likely contributes to a large proportion of chronic leg ulcers seen in this region of the world. Similarly, lymphedema from primary or secondary etiologies causes progressive functional impairment marked by swelling, physical discomfort, disfiguring changes, skin hardening from fibrosis, poor wound healing, recurrent skin infection, and rarely tumors [6].

For both venous leg ulcers and lymphedema, compression is part of standard of care $[6,7]$. With regards to compression therapy for venous leg ulcers, the most recent Cochrane systematic review concluded that multicomponent compression systems are more effective than singlecomponent systems, and two-component bandage systems appear equivalent to four-layer bandages [7]. In resource-replete settings, bandages are applied to the affected $\operatorname{leg}(\mathrm{s})$ at a wound care clinic and left in place for 1 week. A commonly used two-component bandage system consists of the Unna boot (zinc oxide-impregnated paste bandage) as the inner layer, followed by an elastic bandage as the outer layer [7]. Each week, bandages are removed at clinic, the affected leg(s) evaluated, and new bandages applied if still indicated. Patients often continue weekly compression bandages for several weeks to months.

When healthcare providers from an Academic Model Providing Access to Healthcare (AMPATH) wound care clinic in Western Kenya noted that a donated supply of Unna boots and elastic bandages (two-component system) was helping to heal chronic leg ulcers, they reached out to other healthcare providers at AMPATH to explore the potential of finding a local, sustainable solution. AMPATH is a partnership between Moi Teaching and Referral Hospital and Moi University College of Health Sciences in Kenya and a consortium of North American academic medical centers. AMPATH, a President's Emergency Plan for AIDS Relief-United States Agency for International Development (PEPFAR-USAID)supported implementing partner, collaborates with the Ministry of Health to serve a catchment area of over 4 million people and has supported HIV care delivery for over 150,000 patients at over 500 sites across Western Kenya. Using the infrastructure and healthcare delivery model created through HIV care, AMPATH has been providing care for other chronic diseases.

In Western Kenya and similar resource-limited settings, provision of compression therapy is a major challenge due to several barriers: 
availability, affordability, and access to healthcare facilities. Prepackaged two-component compression bandage systems are either locally unavailable or cost-prohibitive for patients, as imported kits cost 7-20 USD per package. The objective of this project is to identify locally sourced routinely used wound care materials to assemble an affordable two-component compression bandage with a sustainable cost model. This was achieved through literature review to identify essential components of a two-component compression bandage and feedback from wound care providers.

\section{METHODS}

To identify essential components of the Unna boot paste bandage, literature review was conducted in MEDLINE ${ }^{\circledR}$ and Embase ${ }^{\circledR}$ using the following search terms: "low cost compression therapy," "affordable compression," "affordable compression therapy," "modified Unna boot," "modified paste bandage," "modified paste bandage compression," "low cost paste bandage," "low cost Unna boot." Articles in English were reviewed. Ingredients used in Unna's paste and the donated supply of Unna boots were noted.

Subsequently, assembly using essential locally available components of a two-component compression bandage occurred. Following application on a healthy leg to demonstrate ease of use and durability, wound care providers at an AMPATH wound clinic were trained to use the compression bandages. Feedback from providers was used to make adjustments to the compression bandages and to determine the cost of each two-component compression bandage kit.

\section{Compliance with ethics guidelines}

This article does not contain any studies with human participants or animals performed by any of the authors.

\section{RESULTS}

Literature review resulted in three relevant articles [8-10], all of which were available in

Table 1 Ingredients used in paste bandages identified in literature review and donated supply

\begin{tabular}{|c|c|c|}
\hline Source & Paste ingredients & Comments \\
\hline $\begin{array}{l}\text { Unna } \\
\text { [12] }\end{array}$ & White gelatin, zinc oxide, glycerin, water & No directions given for preparation \\
\hline $\begin{array}{l}\text { Balaragu } \\
\text { et al. } \\
\text { [8] }\end{array}$ & Zinc oxide, glycerin paste & $\begin{array}{l}\text { Authors comment that gelatin was not included } \\
\text { because it solidifies quickly and is difficult to } \\
\text { transport from pharmacy to bedside }\end{array}$ \\
\hline $\begin{array}{c}\text { Luz et al. } \\
{[10]}\end{array}$ & White gelatin, zinc oxide, glycerin, water & $\begin{array}{l}\text { White gelatin dissolved in warm water, simmering the } \\
\text { solution for } 12 \mathrm{~h} \text {. Then, remaining ingredients } \\
\text { added and solution is cooled in a stainless-steel tray. } \\
\text { This paste is melted in a hot water bath prior to } \\
\text { embedding in the bandage }\end{array}$ \\
\hline $\begin{array}{l}\text { Bodine } \\
{[9]}\end{array}$ & $\begin{array}{l}\text { Gelocast }{ }^{\circledR} \text { : calamine, magnesium aluminum silicate, } \\
\text { glycerin, sorbitol, hexachlorophene, dichlorophene, } \\
\text { zinc oxide }\end{array}$ & $\begin{array}{l}\text { Modified for use with acute sprains and strains by } \\
\text { incorporating fast-setting plaster of Paris }\end{array}$ \\
\hline $\begin{array}{r}\text { Donated } \\
\text { supply }\end{array}$ & $\begin{array}{l}\text { Unna- } \mathrm{Z}^{\circledR} \text { : water, glycerin, zinc oxide, cetearyl alcohol, } \\
\text { ceteareth-20, mineral oil, Cyamopsis tetragonoloba } \\
\text { gum, xanthan gum, imidazolidinyl urea, lactic acid, } \\
\text { methylparaben, propylparaben }\end{array}$ & \\
\hline
\end{tabular}


English. Table 1 summarizes the paste ingredients found in these articles, Unna's teachings, and donated bandages. In all instances, the paste is applied to gauze to create the pasteimpregnated bandage.

As seen in Table 1, the ingredients shared by the various Unna boot paste bandages were zinc oxide and glycerin. With limited local availability of glycerin, the essential locally available components of the inner layer of the twocomponent compression bandage were identified as zinc oxide and gauze, both of which are routinely used in wound care. Elasticity was identified as an essential component of the outer layer and locally available as elastic crepe. Two-component compression bandage kits were made by applying zinc oxide to dry gauze for the inner layer and using elastic crepe as the outer layer. See Fig. 1 for details on assembly. The inner layer gauze measured 10 inches $\times 2 \mathrm{~m}$. Adjustments to assembly of the paste bandage included use of zinc oxide paste instead of zinc oxide ointment due to easier gauze impregnation and cutting the inner layer gauze in half lengthwise to facilitate easier bandaging of the leg, such that there were two rolls of zinc-impregnated gauze each measuring 5 inches $\times 2 \mathrm{~m}$. Continuous local acquisition of all components led to lower price quotes for bulk materials, driving down the production cost and enabling a cost to the patient of 200 KSh (2 USD) per two-component compression bandage kit. This has been considered affordable by patients. The layered compression bandage kits are distributed through a network of AMPATH revolving fund pharmacies located throughout Western Kenya. The revolving fund pharmacy model allows for stable provision of medications and medical supplies by using revenues generated from sales to restock, ameliorating the effects of stock-outs at government facilities [11].

Adjustments to use of the compression bandage have included increasing the frequency of bandage changes from 7 to 3 days during the rainy seasons. If the compression bandage gets wet, then foul odor from microbial overgrowth can occur. For patients who have legs with smaller limb volume, providers have been able to use only one of the two rolls of zinc- impregnated gauze per visit, which reduces the cost for patients as bandages are purchased less frequently. Wound care providers have provided anecdotal reports of healed chronic leg ulcers (from venous stasis, trauma), improved lymphedema, and patient tolerance of compression.

\section{DISCUSSION}

The motivation for, and development of, lowcost locally sourced two-component compression bandages in Western Kenya are described above. There are several limitations and considerations to be addressed in future work.

First, compared with manufactured prepackaged products, these locally sourced paste bandages do not contain preservatives, which have antimicrobial properties. The absence of preservatives could impact the shelflife of the compression bandages. As such, use of these compression bandages as close to assembly as possible is recommended. Providers have been trained and instructed to monitor for infections at every clinical visit. Second, the amount of pressure from compression has not been measured and is variable depending on the operator. This will need to be addressed through measurements on working pressure and pressure on rest so that standardization of compression can occur. Third, beyond the anecdotal reports of healed ulcers, the efficacy of using these compression bandages for managing chronic leg ulcers of venous stasis or traumatic injury etiology and lymphedema needs to be assessed. These studies are ongoing. Reproducibility in similar settings should also be demonstrated.

Lastly, providers' experience to-date suggests that adaptations to the standard use of twocomponent compression bandages in resourcereplete settings are needed to optimize their use in Western Kenya and similar settings. For example, environmental conditions and exposures can affect patients' ability to keep the bandages dry, which is important for minimizing infection risk and maximizing comfort. In addition to experiencing multiple rainy seasons, the average person in Western Kenya is 

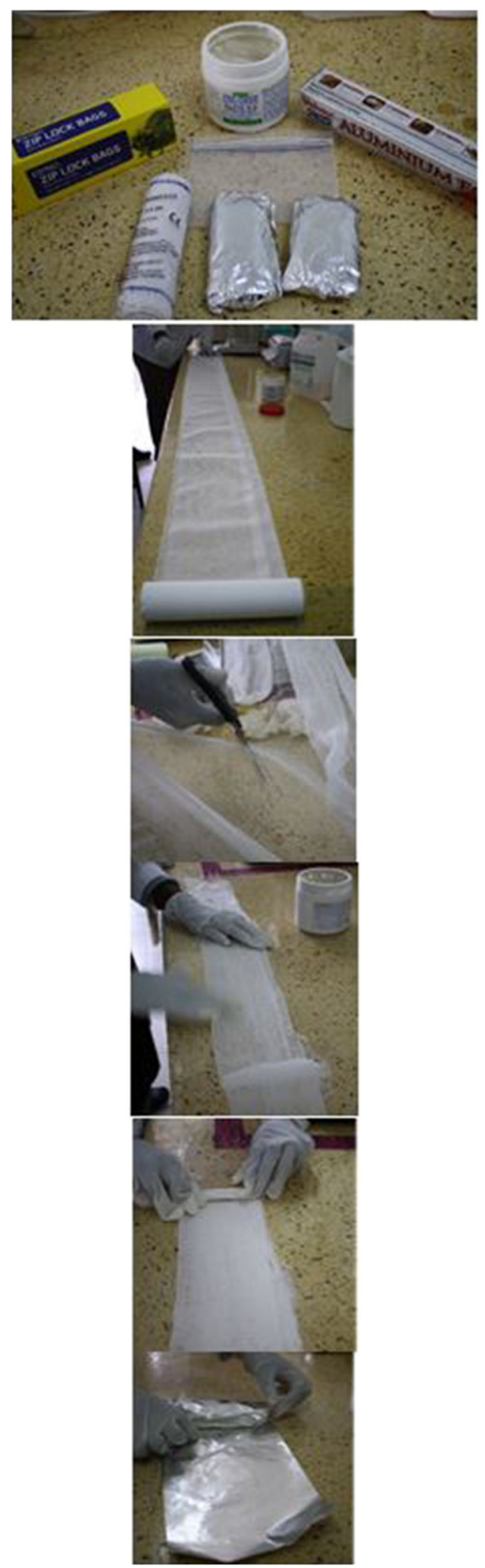

Supplies needed:

White cotton gauze: $2-3 \mathrm{~m}$ in length Zinc oxide paste

Elastic crepe: $5-6$ in $(12.7-15.2 \mathrm{~cm})$ in width Aluminum foil

Plastic zip lock bag Gloves

Surface disinfectant Scissors

1) Clean table or workbench with disinfectant, such as surgical spirit. Put on gloves. Unroll the white gauze on clean surface and measure to length of 2-3 meters. Cut off excess.

2) Depending on desired width, cut the cotton gauze in half lengthwise to produce 2 equal halves. Then fold each piece in half lengthwise.

3) Scoop out a small amount of zinc oxide paste and spread a thin layer over the length of gauze using the tip of fingers. Repeat until entire strip of gauze is coated with paste.

4) Roll up the gauze. Repeat for the other piece of gauze.

5) Wrap each roll of paste-impregnated gauze in aluminum foil to preserve moisture. Then place foil-wrapped gauze pieces and elastic crepe in plastic zip lock bas.

Fig. 1 Step-by-step assembly of low-cost locally sourced two-component compression bandages 
regularly exposed to dirt and dust, as tarmac roads and sidewalks are the exception; the majority of transportation occurs via foot, bicycle, motorbike, or public shared van. As such, providers have increased the frequency of bandage changes to twice weekly as needed. Moreover, use of two-component compression bandages can become a significant recurrent cost, as they are typically applied at a healthcare facility. Patients may need to travel a long distance to reach the health center, leading to additional travel costs and lost income from decreased work productivity. As such, homeand community-based care delivery models utilizing task shifting should be explored for their potential to minimize access and cost barriers.

\section{CONCLUSIONS}

Low-cost locally sourced two-component compression bandages were developed for use in Western Kenya. Their use has been initiated at an AMPATH health center and is poised to meet the need for affordable compression therapy options in Western Kenya. Ongoing studies include evaluation of efficacy in treating chronic leg ulcers and Kaposi sarcoma lymphedema. Future work should address adaptation of the compression bandages for optimal use in Western Kenya and evaluate reproducibility of these bandages in similar settings, as well as consider home- or community-based care delivery models to mitigate transportation costs associated with accessing healthcare facilities.

\section{ACKNOWLEDGEMENTS}

We wish to thank Dr. Lisa Hoo, staff physician at Laguna Honda Hospital, San Francisco, California, for her generous donation of compression bandages. We thank Sara Fletcher for updating the assembly guide for Fig. 1.

Funding. This project was supported, in part, with support from the Indiana Clinical and Translational Sciences Institute funded, in part by Grant Number UL1TR001108 from the National Institutes of Health, National Center for Advancing Translational Sciences, Clinical and Translational Sciences Award. The content is solely the responsibility of the authors and does not necessarily represent the official views of the National Institutes of Health. This project also received support from the Purdue University Office of Engagement. Article processing charges were funded by the authors.

Authorship. All named authors meet the International Committee of Medical Journal Editors (ICMJE) criteria for authorship for this article, take responsibility for the integrity of the work as a whole, and have given their approval for this version to be published.

Disclosures. Aileen Y. Chang, Edith C. Tonui, Douglas Momanyi, Alex R. Mills, Paul Wasike, Rakhi Karwa, Toby A. Maurer and Sonak D. Pastakia have nothing to disclose.

Compliance with ethics guidelines. This article does not contain any studies with human participants or animals performed by any of the authors.

Open Access. This article is distributed under the terms of the Creative Commons Attribution-NonCommercial 4.0 International License (http://creativecommons.org/licenses/ by-nc/4.0/), which permits any noncommercial use, distribution, and reproduction in any medium, provided you give appropriate credit to the original author(s) and the source, provide a link to the Creative Commons license, and indicate if changes were made.

\section{REFERENCES}

1. Harrison MB, Graham ID, Friedberg E, Lorimer K, Vandevelde-Coke S. Regional planning study. Assessing the population with leg and foot ulcers. Can Nurse. 2001;97(2):18-23.

2. Chokotho L, Mulwafu W, Jacobsen KH, Pandit H, Lavy C. The burden of trauma in four rural district 
hospitals in Malawi: a retrospective review of medical records. Injury. 2014;45(12):2065-70.

3. Sanyang E, Peek-Asa C, Bass P, Young TL, Jagne A, Njie B. Injury factors associated with discharge status from emergency room at two major trauma hospitals in The Gambia, Africa. Injury. 2017;48(7):1451-8.

4. Hulme P. Mechanisms of trauma at a rural hospital in Uganda. Pan Afr Med J. 2010;7:5.

5. Ogendi JO, Ayisi JG. Causes of injuries resulting in a visit to the emergency department of a Provincial General Hospital, Nyanza, Western Kenya. Afr Health Sci. 2011;11(2):255-61.

6. Grada AA, Phillips TJ. Lymphedema: diagnostic workup and management. J Am Acad Dermatol. 2017;77(6):995-1006.

7. O'Meara S, Cullum N, Nelson EA, Dumville JC. Compression for venous leg ulcers. Cochrane Datab Syst Rev. 2012;11:CD000265.

8. Balaraju DN, Srinivas CR, Mukhi SV. Modified Unna boot and pinch grafting for chronic non-healing venous leg ulcer. J Cutan Aesthet Surg. 2008;1(1):25-6.

9. Bodine KG. A modified Unna boot for the treatment of foot injuries. J Am Podiatry Assoc. 1967;57(3):125-6.

10. Luz BS, Araujo CS, Atzingen DA, Mendonca AR, Mesquita Filho M, Medeiros ML. Evaluating the effectiveness of the customized Unna boot when treating patients with venous ulcers. An Bras Dermatol. 2013;88(1):41-9.

11. Manji I, Manyara SM, Jakait B, Ogallo W, Hagedorn IC, Lukas S, et al. The revolving fund pharmacy model: backing up the ministry of health supply chain in Western Kenya. Int J Pharm Pract. 2016;24(5):358-66.

12. Bloch I. The practice of skin diseases; Unna's Teachings for Students and Physicians, summarized and presented by Ivan Bloch. Urban \& Schwarzenberg, Berlin. 1908. https://babel.hathitrust.org/cgi/ pt?id=uc1.b4620009; view=1up;seq=195; size=125. Accessed 13 Feb 2018. 